\title{
A comparative study on the use of fly ash and phosphogypsum in the brick production
}

\author{
SELÇUK TÜRKEL* and EMRAH AKSIN
}

Civil Engineering Department, Dokuz Eylül University, İzmir, 35160, Turkey

e-mail: selcuk.turkel@deu.edu.tr

MS received 4 November 2011; revised 26 March 2012; accepted 26 June 2012

\begin{abstract}
Over 15 million tons of fly ash (FA) and 3 million tons of phosphogypsum (PG) are produced in Turkey every year. The utilization of these industrial by-product materials is important in terms of environmental and economical issues are concerned. The main purpose of this study is to evaluate the technical possibilities of incorporating FA and PG in production of building blocks. Various mixtures were prepared by incorporating these industrial wastes by replacing clay with seven different weight proportions $(0 \%, 5 \%, 10 \%, 15 \%, 20 \%, 25 \%$ and $30 \%)$. All specimens were fired at $1000^{\circ} \mathrm{C}$ peak temperature. The physical and mechanical properties of all specimens such as; unit weight, compressive strength, flexural strength, dimensional stability and water absorption values were recorded. The effect of PG incorporation on the properties of samples seems to be more dominant than the effect of FA incorporation. The test results showed that; PG incorporation increased the unit weight and mechanical strength values while lowering the water absorption values. Utilization of these wastes additives is not only for conservation of clay resources, but also an alternative solution to a difficult and expensive waste disposal problems.
\end{abstract}

Keywords. Fly ash; phosphogypsum; clay; brick; physical and mechanical properties.

\section{Introduction}

Brick is one of the most widely used conventional construction materials throughout the world since ancient times by using local clayey matter (Warren 1999; Collepardi 1990; Franke \& Schoppe 1989). However, nowadays conservation of natural resources and utilization of industrial by-products are very important issues.

The construction materials industry has always shown a receptive attitude to research into new materials (Giuseppe \& Eduardo 2009; Agarwal \& Gulati 2007). In brick production, many research has been implemented in terms of utilization of different waste products (Dominguez \& Ullmann 1996; Wiebusch \& Seyfried 1997; Lin 2006; Yang et al 2009; Çiçek \& Tanrıverdi 2007; Abalı et al 2007).

*For correspondence 
Fly ash (FA) and phosphogypsum (PG) are significant by-products of thermal power plants and phosphoric acid-based fertilizer industry, respectively. Generally, these wastes create disposal problems as well as environmental pollution on a large scale throughout the world (Kumar 2003). The waste products also contain hazardous ingredients such as heavy metals in FA and $\mathrm{P}_{2} \mathrm{O}_{5}$ in phosphogypsum.

FA is generally evaluated in cement and concrete production as an inexpensive pozzolanic blending material (Pei-wei et al 2007). Also, recent research results showed that FA might improve the compressive strength of bricks and make them more resistant to frost (Lingling et al 2005).

PG has limited utilization areas in construction sector due to the presence of undesirable impurities such as $\mathrm{P}_{2} \mathrm{O}_{5}$, fluorides, organic matter and alkalies (Singh \& Garg 1997; Garg et al 1996). Utilization of PG has been researched in production of artificial aggregates and in road stabilization. PG has also been tried as a raw material for wallboard and plaster applications after purification or calcination processes (Pressler 1984; Singh et al 2003). PG has also been tested in the manufacture of Portland cement industry as a substitute for natural gypsum and for the reduction of clinkerization temperature (Altun \& Sert 2004; Kacimi et al 2006). However, the treatment of PG is very costly and thus, its use in cement industry has not gained much popularity. Limited studies on utilization of PG in brick and adobe production gave encouraging results but the product needed high compaction energy (Kumar 2002; Ajam et al 2009; Cultrone et al 2005).

In Turkey, over 15 million tons FA (Köseoğlu et al 2010) and 3 million tons of PG (Çoruh \& Ergun 2010) are produced per annum. However, utilization of FA and PG is considerably lower when compared to other developed countries due to difficulties in procuring these wastes with consistent quality. Lack of research on this topic also contributes to this low usage.

Researchers are seeking new application areas for FA and PG that would be more environmentally sound to utilize by-products rather than to dump them. This research has been initiated with the perspective of utilization of these by-products in the production of bricks. Second benefit of the project will be the conservation of natural clayey soil.

\section{Experimental study}

\subsection{Materials}

The materials used for the production of solid bricks were fly ash (FA), weathered phosphopypsum (PG), clay (C) and water. FA used in this study was procured from the thermal power plant, which is located in Western Turkey. Based on chemical characteristics presented in table 1, FA can be classified as class-F according to ASTM C 618 (2008). The total amount of $\mathrm{SiO}_{2}, \mathrm{Al}_{2} \mathrm{O}_{3}$ and $\mathrm{Fe}_{2} \mathrm{O}_{3}$ is $87.38 \%$, which was a larger quantity than the value given by ASTM C 618 as the standard for a type F class fly ash. PG was a by-product of BandırmaTurkey fertilizer plant. It was procured from open-air (weathered) waste storage areas. Clay has been taken from a local brick maker in Turgutlu-Manisa, Turkey. It contains significant amounts of silicate minerals (52\%). According to chemical composition of clay, it can be classified as montmorillonite clay mineral (Swamy 1986). The chemical analyses of these materials are presented in table 1. Specific gravities of clay, fly ash and phosphogypsum are $2.35,2.27$ and 2.92, respectively. The type of water used in the experiments was tap water. 
Table 1. Chemical analysis of clay, fly ash and phosphogypsum.

\begin{tabular}{lccc}
\hline Constituent (\%) & $\mathrm{C}$ & $\mathrm{FA}$ & PG \\
\hline $\mathrm{SiO}_{2}$ & 52.7 & 56.47 & 3.20 \\
$\mathrm{Al}_{2} \mathrm{O}_{3}$ & 20.11 & 22.88 & 0.73 \\
$\mathrm{Fe}_{2} \mathrm{O}_{3}$ & 5.28 & 8.03 & 0.20 \\
$\mathrm{CaO}$ & 2.60 & 4.06 & 32.26 \\
$\mathrm{Na} 2 \mathrm{O}$ & 1.20 & 2.14 & - \\
$\mathrm{MgO}$ & 3.75 & 1.92 & 0.02 \\
$\mathrm{~K}_{2} \mathrm{O}$ & 3.69 & 1.69 & - \\
$\mathrm{SO}_{3}$ & - & 0.9 & 44.15 \\
$\mathrm{TiO}_{2}$ & 0.83 & 0.57 & - \\
$\mathrm{P}_{2} \mathrm{O}_{5}$ & - & - & 0.35 \\
$\mathrm{LOI}$ & 7.84 & 0.91 & 21.03 \\
\hline
\end{tabular}

\subsection{Mixture proportions, preparation and test procedure of specimens}

In order to compare the effect of additives (FA and PG) on the properties of compositions, their proportions $(0 \%, 5 \%, 10 \%, 15 \%, 20 \%, 25 \%$ and $30 \%)$ were kept constant in all mixes.

The mix proportions of FA, PG and control specimens $(\mathrm{C})$ are presented in table 2 . As can be seen from table 2, the plasticity water for pure clay samples has been selected $27 \%$ (by weight) according to the Turkish standard TSE 4790 (1986). However, in other mixtures plasticity water has increased according to the replacement proportions.

The following mixing sequence was implemented to achieve a uniform workable mixture for each composition.

(i) Clay materials have been dried in oven at $105^{\circ} \mathrm{C}$. The dried clay was ground and sieved from $2 \mathrm{~mm}$ sieve. The air-dried PG has been ground to $2 \mathrm{~mm}$ fineness.

Table 2. Mix proportions of fly ash, weathered phosphogypsum and clay materials.

\begin{tabular}{lcccc}
\hline & \multicolumn{3}{c}{ Constituent materials (\%) } \\
\cline { 2 - 5 } Mix designation & Plasticity water* & C & FA & PG \\
\hline C (control) & 27 & 100 & 0 & 0 \\
CFA5 & 28 & 95 & 5 & 0 \\
CFA10 & 33 & 90 & 10 & 0 \\
CFA15 & 38 & 85 & 15 & 0 \\
CFA20 & 38 & 80 & 20 & 0 \\
CFA25 & 39 & 75 & 25 & 0 \\
CFA30 & 39 & 70 & 30 & 0 \\
CPG5 & 29 & 95 & 0 & 5 \\
CPG10 & 32 & 90 & 0 & 10 \\
CPG15 & 33 & 85 & 0 & 15 \\
CPG20 & 35 & 80 & 0 & 20 \\
CPG25 & 36 & 75 & 0 & 25 \\
CPG30 & 39 & 70 & 0 & 30 \\
\hline
\end{tabular}

*Water plasticity by weight for total solid content 


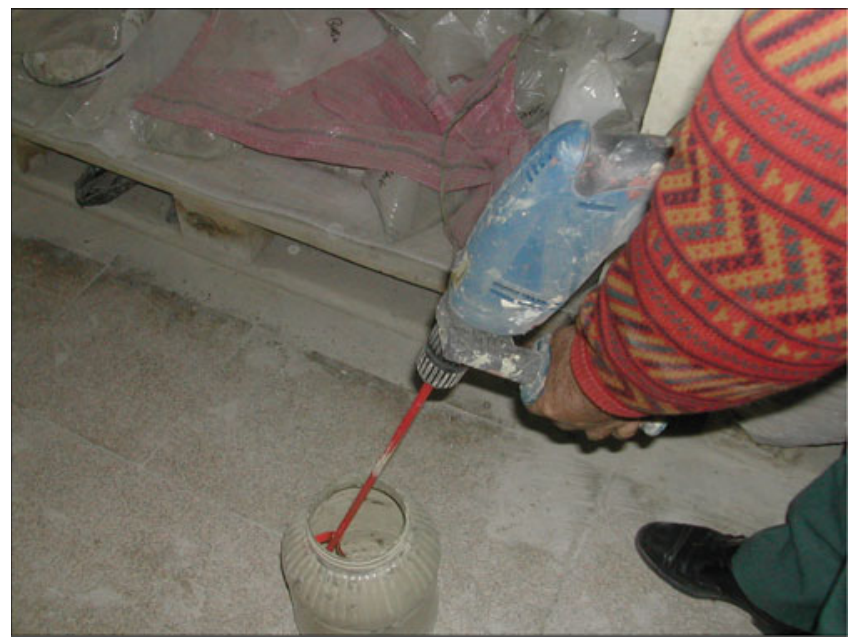

Figure 1. Mixing of materials.

(ii) For control samples (C), clay paste was prepared by adding $27 \%$ water (by weight) and then kept in plastic bags for $24 \mathrm{~h}$. The blended samples were initially mixed about $3 \mathrm{~min}$ in dry state and additionally wet mixed for $2 \mathrm{~min}$ with the machine as shown in figure 1. Similarly, pastes were kept in plastic bags for $24 \mathrm{~h}$ to prevent rapid evaporation. Mixing operation was realized by using mixer machine shown in figure 1 .

(iii) Finally, after $24 \mathrm{~h}$ pastes were prepared by means of a manual extraction device shown in figure 2 that was developed for this investigation.

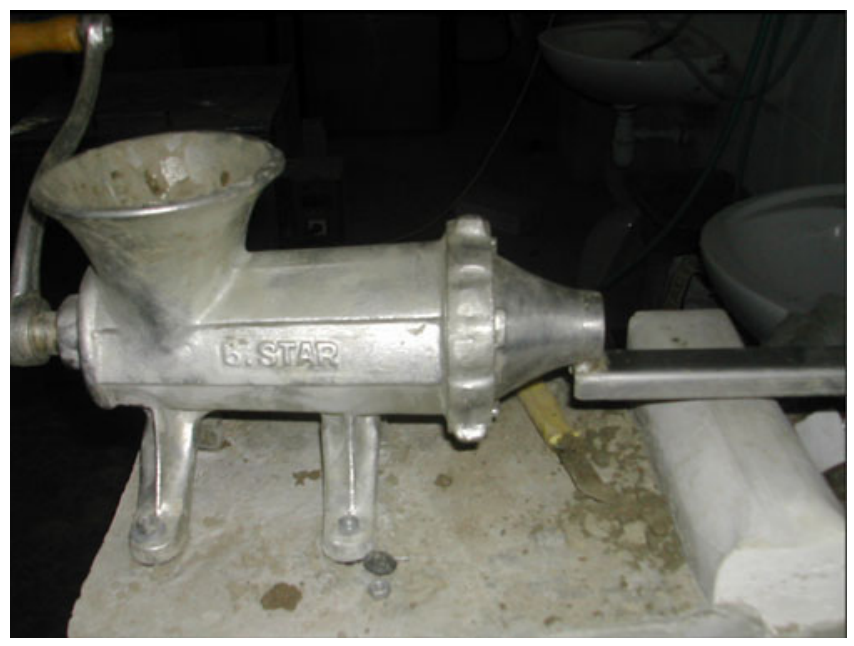

Figure 2. Forming device of clay dough. 


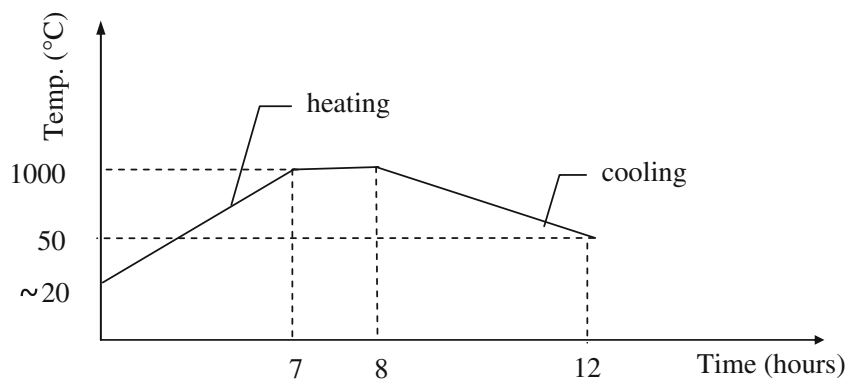

Figure 3. Firing regime.

The wet samples were dried for $24 \mathrm{~h}$ in laboratory conditions and then were placed in the oven for an extra $24 \mathrm{~h}$ at $105^{\circ} \mathrm{C}$. The weight and length measurements of samples were taken after cooling. Afterward, they were fired at $1000^{\circ} \mathrm{C}$ (which is the temperature most frequently used in brick industry) in a high temperature electric oven for $8 \mathrm{~h}$. The heat regime is shown in figure 3 .

The addition of FA and PG caused colour changes in the brick depending on the additive type and their proportions. While control samples were reddish toner (figure 4a), the samples

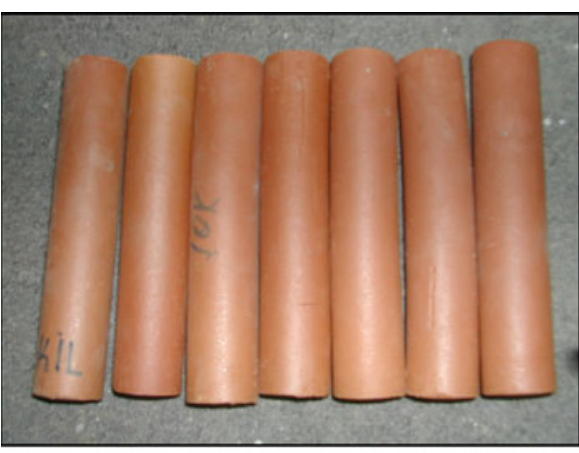

(a)

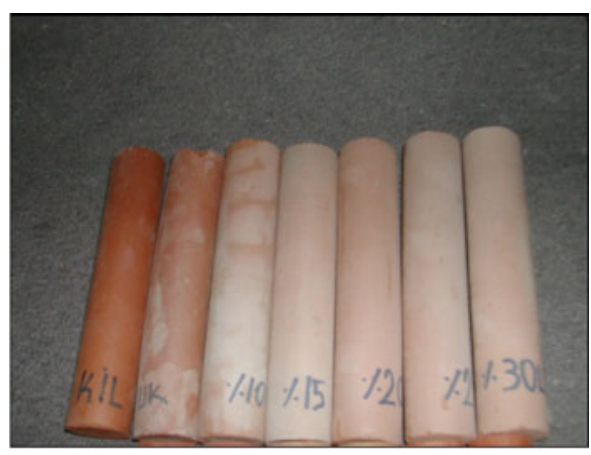

(b)

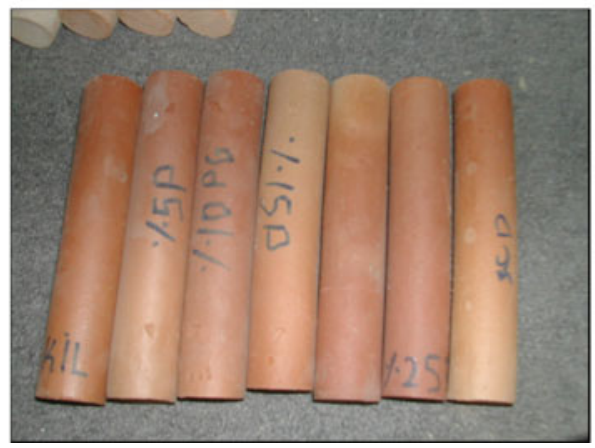

(c)

Figure 4. The colours of the brick specimens after firing at $1000^{\circ} \mathrm{C}$. (a) Pure clay materials; (b) FA added clayey materials and (c) PG added clayey materials. 


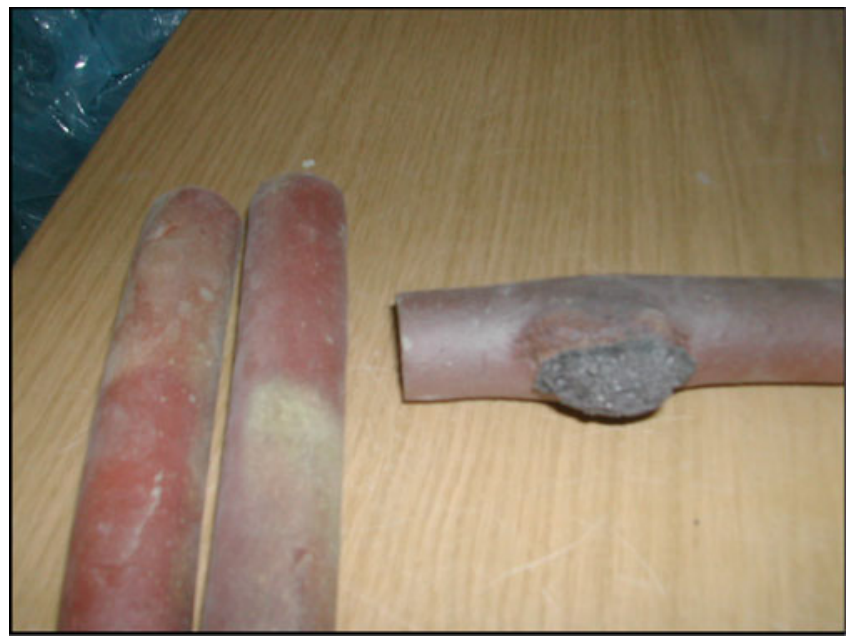

Figure 5. The appearance of the samples after $1200^{\circ} \mathrm{C}$ firing $(10 \% \mathrm{FA}+90 \% \mathrm{C}$ mixture at left; damaged pure clay sample at right).

containing FA were in a light pink colour (figure 4b). The samples with PG have also reddish tones. However, the surface of these specimens was slightly mottled (figure 4c).

During preliminary experiments, control specimens were damaged over $1000^{\circ} \mathrm{C}$ of firing temperatures. However, blended specimens (especially FA series) were more resistant to higher firing temperatures (figure 5). This result indicates that the blending procedure is beneficial in terms of achieving superior mechanical and physical properties. Indeed, Cultrone et al. (2005) observed that the porosity of the brick depends directly on the mineralogical composition of the raw material and the firing temperature. However, generally bricks fired at high temperatures are more vitreous and undergo changes in size and porosity (Cultrone et al 2005).

In order to determine unit weight, compressive strength, flexural strength, water absorption and shrinkage values of all mixtures $27 \mathrm{~mm}$ diameter and different length of cylindrical samples were prepared. The dimensions and the number of the specimens, which were used in the tests for each mixture, are presented in table 3.

Table 3. Dimensions and the number of the specimens for each mixture.

\begin{tabular}{lcc}
\hline Test & $\begin{array}{c}\text { Dimensions of specimens }(\mathrm{mm}) \\
\text { (diameter } \times \text { length) }\end{array}$ & $\begin{array}{c}\text { Number of } \\
\text { specimens }\end{array}$ \\
\hline Oven dry unit weight & $27 \times 80$ & 6 \\
Compressive strength & $27 \times 40$ & 10 \\
Flexural strength & $27 \times 160$ & 6 \\
Drying shrinkage & $27 \times 160$ & 6 \\
Total shrinkage & $27 \times 160$ & 6 \\
Water absorption & $27 \times 80$ & 6 \\
\hline
\end{tabular}




\section{Test results and discussion}

\subsection{Water requirement of mixtures for plasticity}

Table 2 gives the water requirement of specimens for optimum workability. Water requirement of these mixtures varied between $27 \%$ and $39 \%$ by weight. Water requirement increased with the type and replacement ratios of the blending materials (FA and PG). TSE 4790 (1986) recommends a plasticity water ratio values between $25 \%$ and $65 \%$. Also, the Standard states that, if the clay material requires a plasticity water less than $25 \%$ or more than $65 \%$, it can not be used in the production of clay bricks. Therefore, these values can be classified as appropriate in terms of water requirement of clayey mixtures.

\subsection{Unit weight}

The unit weight values of all samples were determined according to Turkish Standard TSE 705 (1979) and shown in figure 6. As can be seen from figure 6, the average unit weight value for control samples is $1.65 \mathrm{~g} / \mathrm{cm}^{3}$. However, unit weight values of the PG incorporated samples increased up to $1.75 \mathrm{~g} / \mathrm{cm}^{3}$ for $30 \%$ of PG addition. In contrast, FA incorporation decreased the unit weight of test specimens. The lowest unit weight was obtained as $1.25 \mathrm{~g} / \mathrm{cm}^{3}$ for $30 \%$ of FA addition. FA contains unburned coal particles but, they are burned during the brick firing process in oven. Therefore, the product is lighter due to the formation of pores in the brick. The similar conclusion was reported by Abalı et al (2007). This indicates that the use of the FA as additive in clayey materials may reduce the unit weight of bricks considerably.

\subsection{Mechanical strength}

The flexural and compressive strength tests were performed on all bone-dry specimens. Flexural strength test was performed on six specimens from each mixture tested by center point loading configuration with a span of $10 \mathrm{~cm}$. The results indicated are the average of six specimens. Compressive strength tests were performed on ten cylinder specimens.

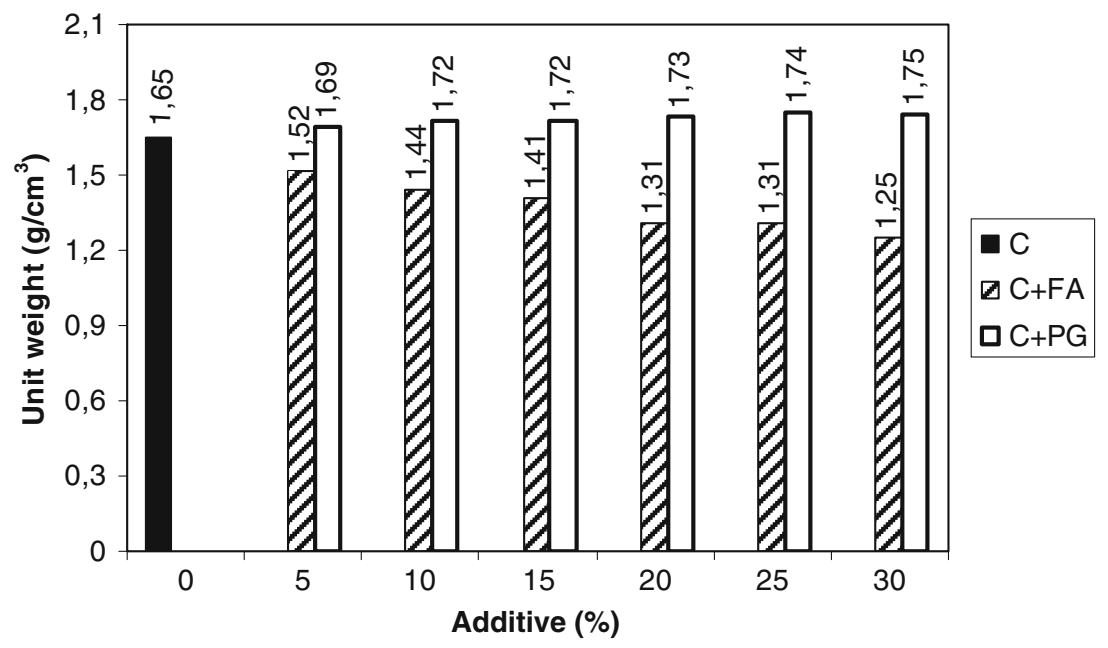

Figure 6. Unit weight of samples. 


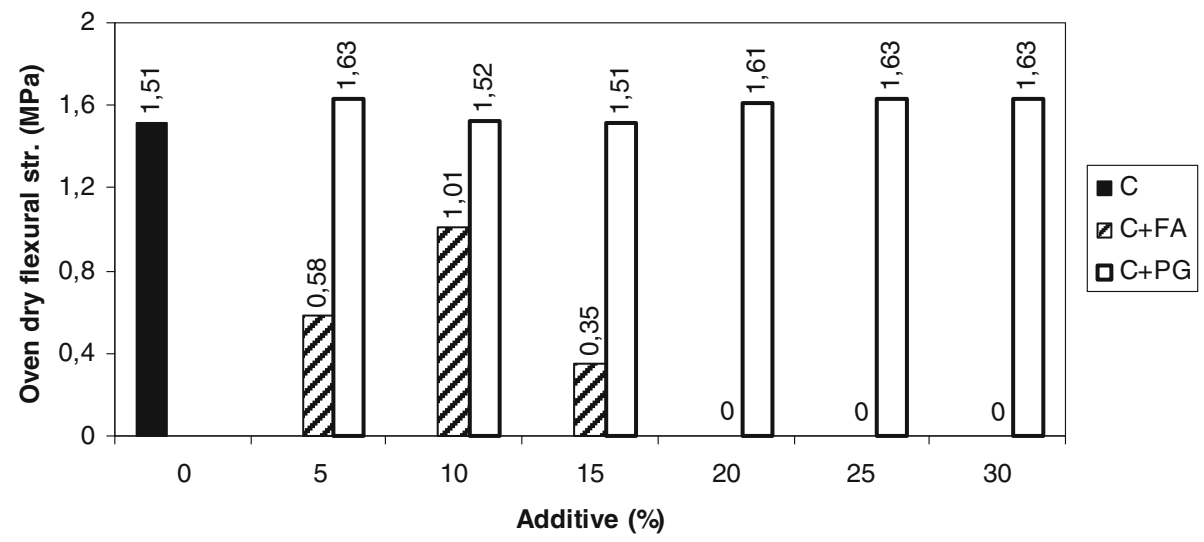

Figure 7. Oven dry $\left(\right.$ at $\left.105^{\circ} \mathrm{C}\right)$ flexural strength of samples.

Average flexural strength values of oven dried (at $105^{\circ} \mathrm{C}$ ) and fired (high temperature at $1000^{\circ} \mathrm{C}$ ) samples are shown in figures 7 and 8 , respectively.

As can be seen from figure 7, oven-dry flexural strength has increased with the increasing PG replacement ratios compared to the control samples. However, flexural strength has decreased with the increasing FA content. In fact, the flexural strength of samples incorporating $20 \%, 25 \%$ and $30 \%$ FA could not be measured due to their poor structure formation. The highest oven dry flexural strengths were obtained with PG addition. The maximum oven dry flexural strength of PG addition sample is $8 \%$ higher than control samples.

Higher flexural strength values were obtained in case of firing at $1000^{\circ} \mathrm{C}$ compared to those of oven-dry samples (figure 8). This behaviour has been observed at all specimens. However, FA and PG containing specimens are weaker than the control specimens. Increase of blending material caused reductions (up to 60\%) in the flexural strength of specimens fired at $1000^{\circ} \mathrm{C}$.

The compressive strength values of the samples fired at $1000^{\circ} \mathrm{C}$ are given in figure 9 . Compressive strength values for control and all the PG samples were over $24 \mathrm{MPa}$ (which is the minimum compressive strength indicated by the TS 705 standard). As can be seen from figure 9, in all the samples the highest compressive strength was obtained by $10 \%$ PG incorporation. The

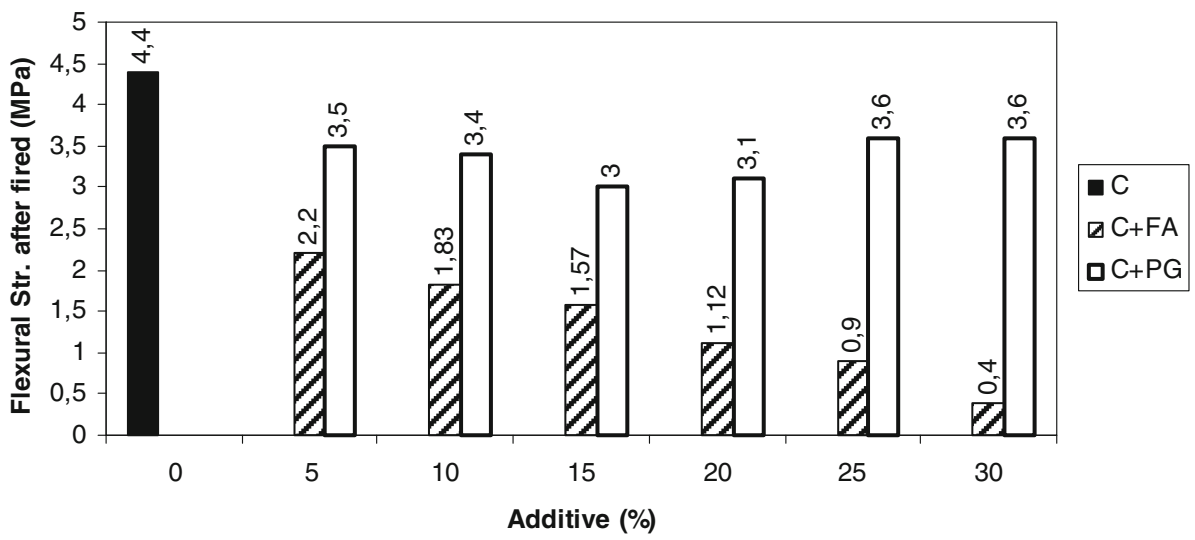

Figure 8. Flexural strength of samples after firing (high temperature heating at $1000^{\circ} \mathrm{C}$ ). 


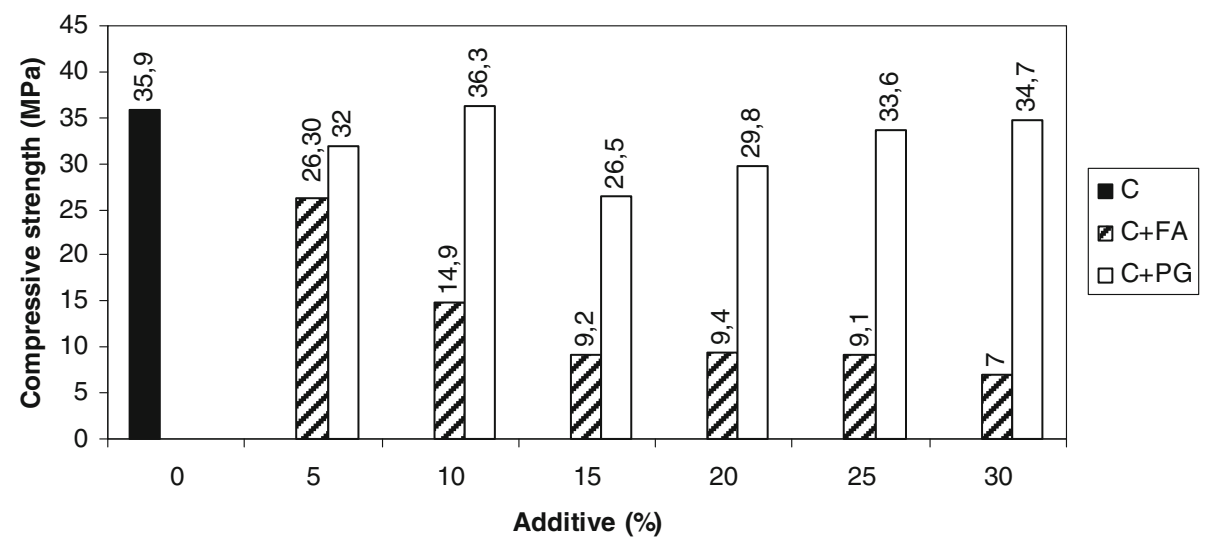

Figure 9. Compressive strength of samples after firing (high temperature heating at $1000^{\circ} \mathrm{C}$ ).

mixtures with PG had also low water absorption and high unit weight values. On the contrary, compressive strength values had decreased with the increasing of FA ratio, due to their low unit weight (figure 6) and high water absorption properties (figure 10).

\subsection{Water absorption}

The water absorption is a major factor for the durability of bricks. The high absorption of water would contribute to a rapid deterioration of this type of material (Ajam et al 2009). The water absorption test was made according to the procedure described in the TS EN 771-1 standard (2005).

The water absorption values of all the samples are shown in figure 10. Water absorption of the samples varied between $19 \%$ and $38 \%$. The average water absorption was $20 \%$ for the control specimens which is over $18 \%$ (maximum water absorption indicated by the TS EN 771-1 standard).

As can be seen from figure 10, water absorption values of all specimens have increased with the increasing FA content. However, water absorption values of PG incorporated specimens were

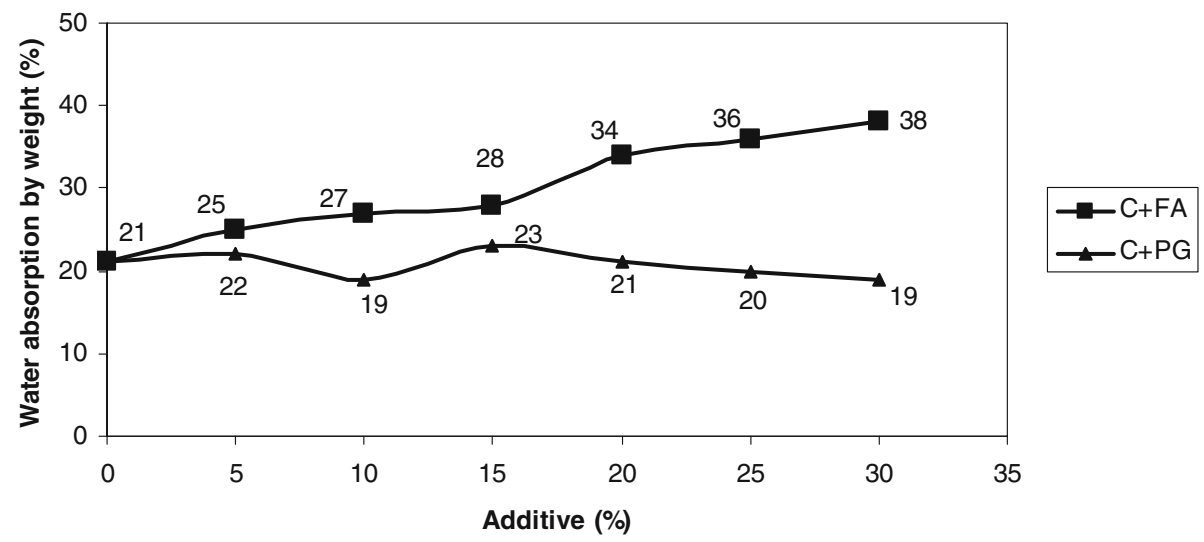

Figure 10. Water absorption of the samples by weight (\%). 
generally lower than the control specimen which were almost equal to the maximum allowable water absorption value indicated by the TS EN 771-1 standard. The low water absorption values of PG series can be attributed to the sintering reaction between the raw clay and the PG firing at high temperature that leads to formation of a more denser and impermeable inner structure.

\subsection{Shrinkage}

The magnitude of shrinkage depends primarily on the drying and the firing procedures. The water that is necessary for obtaining plasticity is evaporated through the drying process. When a clay composition is subjected to the desiccation, the elementary particles tend to approach and imbricate one into the other. This process induces shrinkage on one hand and on the other hand, cohesion following this operation (Ajam et al 2009).

The drying shrinkage depends primarily on clay mineralogical composition and texture, shaping conditions of the paste and used water quantities, and percentage of the degreasing material (sand, crushed bricks, etc.), clay in the formulation and the drying procedures (Ajam et al 2009).

During firing, another type of shrinkage, called firing shrinkage occur. The dimensional variation (expansion and shrinkage) is related to the elimination of the components (with eventually creation of an internal gas pressure) and to the structural reactions and transformations (Ajam et al 2009).

The drying shrinkage (first, air drying at normal temperature environments and then in oven drying at $105^{\circ} \mathrm{C}$ ) and total shrinkage (after firing at high temperature) of the samples are shown in figures 11 and 12, respectively. The drying shrinkage is expressed by the ratio of the length difference before and after drying to the initial length.

In all the samples, the drying shrinkage varied between $3.78 \%$ and $7.65 \%$. The drying shrinkage value was $6.30 \%$ for the control specimen. As can be seen from figure 11, the drying shrinkage values have increased with increasing the PG ratio compared to the control samples. In contrast, the shrinkage values of the samples have decreased with the increasing FA ratio. In all the samples, the lowest shrinkage value was obtained for the mixture with $30 \%$ FA content. The lowest shrinkage value of the FA incorporating sample can be attributed to the mineralogical composition and texture of the additive (Ajam et al 2009).

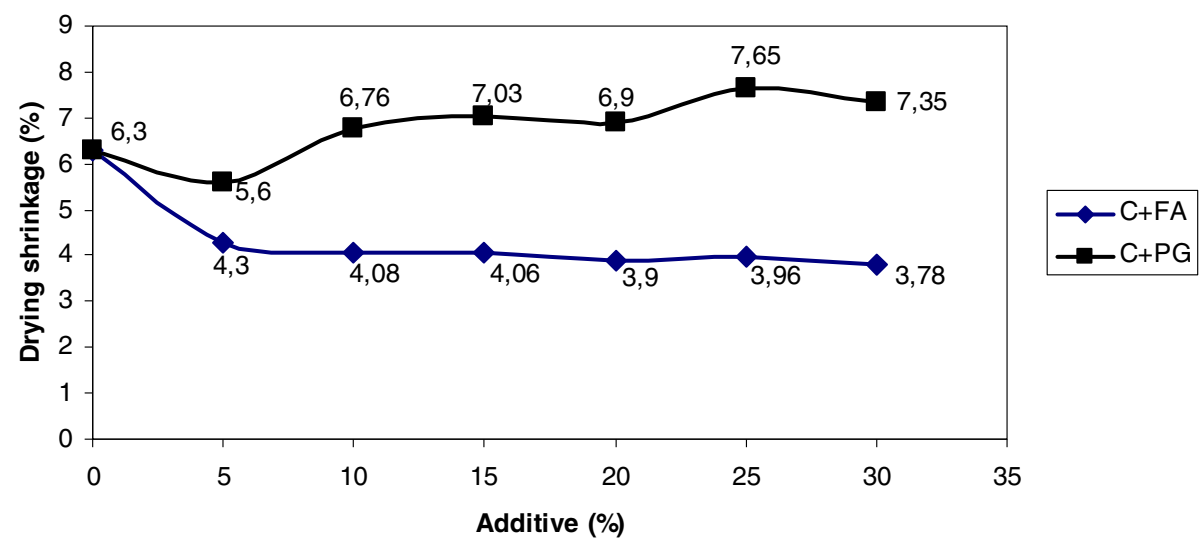

Figure 11. The drying shrinkage of the samples (first air drying at normal temperature environments and then in oven drying at $105^{\circ} \mathrm{C}$ ). 


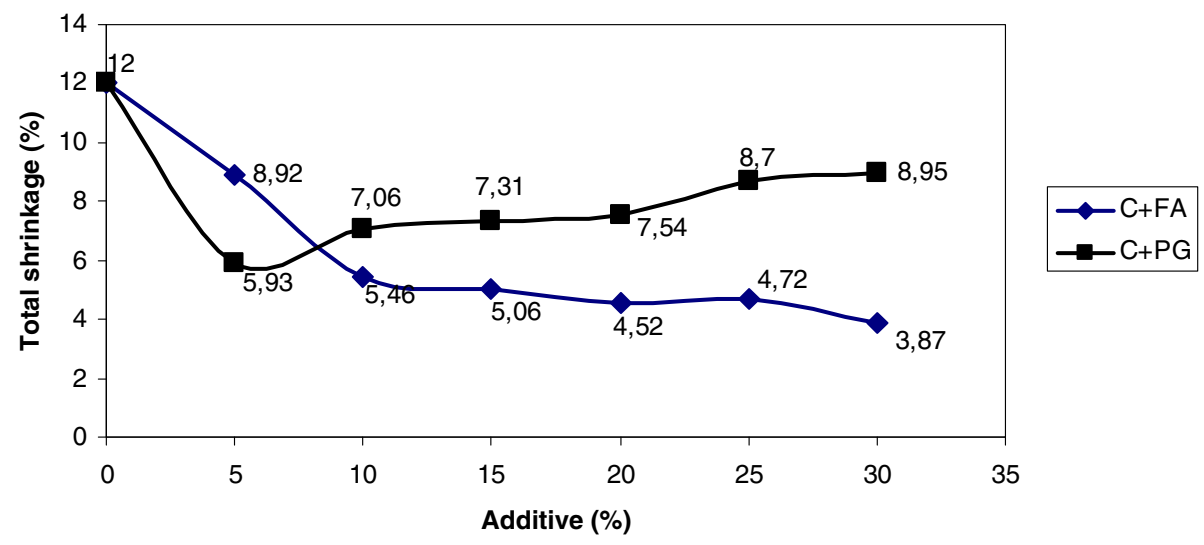

Figure 12. Total shrinkage of the samples (firing high temperature at $1000^{\circ} \mathrm{C}$ ).

As expected, the total shrinkage values of the samples (firing at high temperature after drying) are greater than both control and oven dried samples. As can be seen from figure 12, generally the total shrinkage values of specimens decreased with the increasing of the blending ratio when compared to the control mixture.

Figure 13 illustrates the plasticity water need and the total shrinkage values of all samples. As can be seen from figure 13, the total shrinkage values of the samples have decreased with the increasing amounts of plasticity water and additives ratio. There seems to be a contradiction between decreasing shrinkage values with the increasing of plasticity water need. This contradiction can be attributed to the different hydration reactions of the additive materials. It is

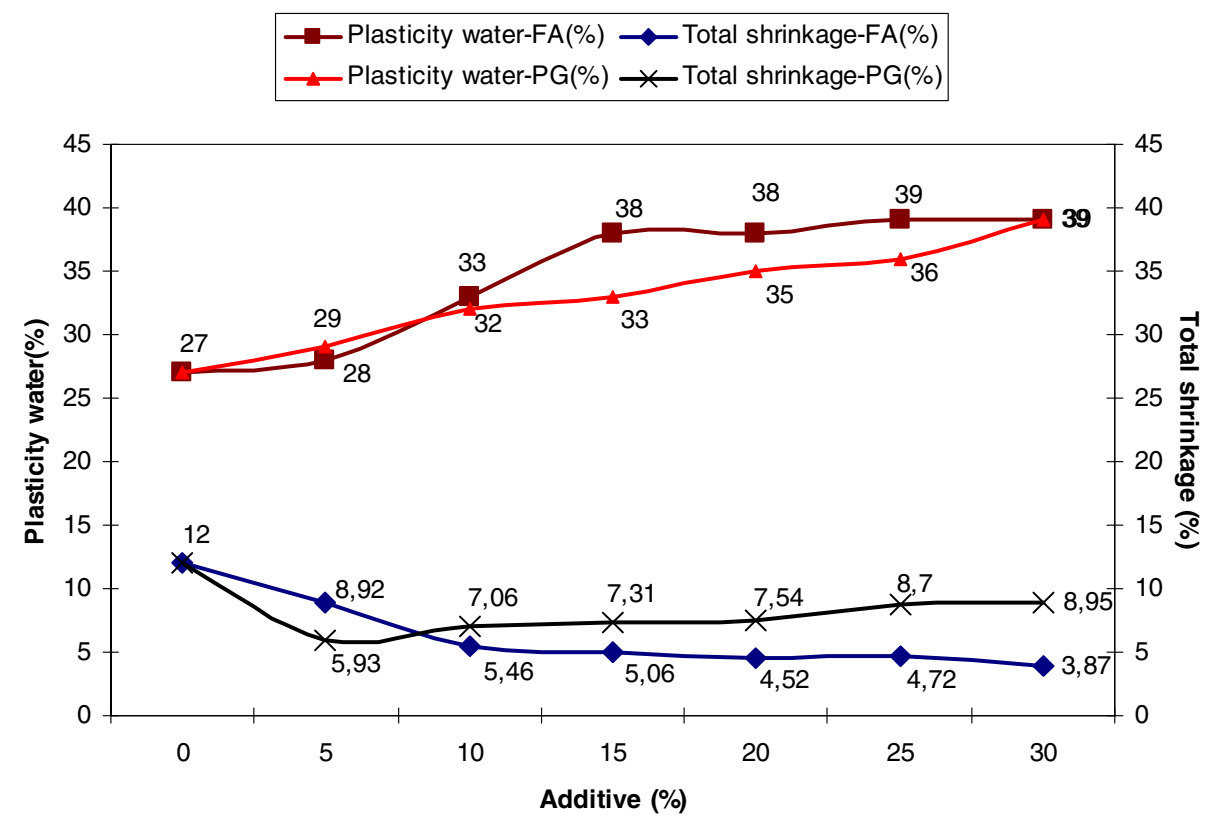

Figure 13. Plasticity water and total shrinkage of the samples. 
well-known that hydration rate develops slower by incorporation of FA compared to fast gypsum hydration. Also, in terms of moisture, PG holds more moisture than FA after hydration. In this regard, due to lower water content of FA mixtures after hydration, shrinkage values may decrease. Generally, it can be said that incorporating of additives has a positive effect in reducing shrinkage of bricks.

\section{Conclusions}

The main objective of this research was to investigate the possibility of fly ash and phosphogypsum utilization as additives for the production of solid bricks. The following conclusions can be drawn based on the results presented in this paper.

The plasticity water for pure clay samples was found $27 \%$ by weight. Water requirement increased with the incorporation of FA and PG. The unit weight of control specimens was $1.65 \mathrm{~g} / \mathrm{cm}^{3}$. The unit weight values of the specimens increased with the incorporation of PG. In contrast, the addition of FA decreased the unit weight values of specimens.

Oven-dry flexural strength values of the specimens incorporating PG increased with the increasing of PG ratios compared to the control mixture. In contrast, oven dry flexural strength values of the samples incorporating FA decreased with the increasing of FA ratios. However, the highest flexural strength values after firing was obtained with the control samples compared to blended mixtures.

Generally, water absorption values of the samples in contrast to PG series, increased with the increasing of FA ratios compared to the control mixture. The minimum water absorption values were obtained by $10 \%$ and $30 \%$ PG addition.

The drying shrinkage of the samples incorporating PG increased with the increasing the PG ratio compared to the control mixture. In contrast, drying shrinkage values decreased with the increasing of FA ratios. The total shrinkage values of all samples decreased with the increasing FA and PG ratios when compared to the control mixture.

\section{References}

Abalı Y, Yurdusev M A, Zeybek M S and Kumanlığlu A A 2007 Using phosphogypsume and boron concentrator wastes in light brick production. Constr. Build. Mater. 21: 52-56

Agarwal S K and Gulati D 2007 Utilization of industrial wastes and unprocessed microfillers for making cost effective mortars. Constr. Build. Mater. 20: 999-1004

Ajam L, Ouezdou M B, Felfoul H S and El Mensi R 2009 Characterization of the Tunisian phosphogypsum and its valorization in clay bricks. Constr. Build. Mater. 23: 3240-3247

Altun I A and Sert Y 2004 Utilization of weathered phosphogypsum as set retarder in Portland cement. Cem. Concret. Res. 34(4): 677-80

ASTM C618 2008 Standard specification for fly ash and raw or calcined natural pozzolan for use as mineral admixture in Portland cement concrete. Annual Book of ASTM Standards

Collepardi M 1990 Degradation and restoration of masonry walls of historical buildings. Mater. Struct. 23: $81-102$

Cultrone G, Sebastian E and Torre M J 2005 Mineralogical and physical behaviour of solid bricks with additives. Constr. Build. Mater. 19: 39-48

Çicek T and Tanrıverdi M 2007 Lime based steam autoclaved fly ash bricks. Constr. Build. Mater. 21: $1295-1300$

Çoruh S and Ergun O N 2010 Use of fly ash, phosphogypsum and red mud as a liner material for the disposal of hazardous zinc leach residue waste. J. Hazard. Mater. 173: 468-473 
Dominguez E A and Ullmann R 1996 Ecological bricks made with clays and steel dust pollutants. Appl. Clay Sci. 11: 237-49

Franke L and Schoppe I 1989 Deterioration of historic brick buildings. In: N S Baer, C Sabbioni, A I Sors (eds) Proceedings of the European Symposium on Science, Technology and European Cultural Heritage. Italy: Bologna; 418-21

Garg M, Singh M and Kumar R 1996 Some aspects of the durability of a phosphogypsum-lime-fly ash binder. Constr. Build. Mater. 10: 273-9

Giuseppe C and Eduardo S 2009 Fly ash addition in clayey materials to improve the quality of solid bricks. Constr. Build. Mater. 23: 1178-1184

Kacimi L, Simon-Masseron A, Ghomari A and Derriche Z 2006 Reduction of clinkerization temperature by using phosphogypsum. J. Hazard. Mater. B 137: 129-37

Koseoglu K, Polat M and Polat H 2010 Encapsulating fly ash and acidic process waste water in brick structure. J. Hazard. Mater. 176: 957-964

Kumar S 2002 A perspective study on fly ash-lime-gypsum bricks and hollow blocks for low cost housing development. Constr. Build. Mater. 16: 519-25

Kumar S 2003 Fly ash-lime-phosphogypsum hollow blocks for walls and partitions. Building and Environment 38: 291-295

Lin K L 2006 Feasibility study of using brick made from municipal solid waste incinerator fly ash slag. $J$. Hazard. Mater. B 137: 1810-6

Lingling X, Wei G, Tao W and Nanru Y 2005 Study on fired bricks with replacing clay by fly ash in high volume ratio. Constr. Build. Mater. 19: 243-7

Pei-wei G, Xiao-lin L, Hui L, Xiaoyan L and Jie H 2007 Effects of the fly ash on the properties of environmentally friendly dam concrete. Fuel 86: 1208-11

Pressler W J 1984 By-product gypsum. In: Chemistry and technology of gypsum. Atlanta, GA, USA: ASTM Special Technical Publication, 105-15

Singh M and Garg M 1997 Durability of cementitious binder derived from industrial wastes. Mater. and Struct. 30: 607-12

Singh M, Verma C L and Garg M 2003 Processing of phosphogypsum for value added building materials. Recycling and reuse of waste materials. In: Proceedings of the international symposium, Dundee, UK, $165-72$

Swamy R N (ed) 1986 Concrete technology and design, Volume 3, Cement replacement materials, London: Surrey University Press

Warren J 1999 Conservation of brick. Oxford: Butterworth Heinemann

Wiebusch B and Seyfried CF 1997 Utilization of sewage sludge ashes in the brick and tile industry. Water Sci. Technol. 36: 251-8

Yang J, Liu W, Zhang L and Xiao B 2009 Preparation of load-bearing building materials from autoclaved phosphogypsum. Constr. Build. Mater. 687-693.

TSE 7051979 Turkish Standard Test Method for Solid Bricks and Vertically Perforated Bricks, Ankara, Turkey: Turkish Standards Institute

TSE 47901986 Turkish Standard Test Method for Common Bricks and Roofing Tile Clays, Ankara, Turkey: Turkish Standards Institute

TS EN 771-1 2005 Turkish Standard Test Method for 'Specification for masonry units-Part 1: Clay masonry units', Ankara, Turkey: Turkish Standards Institute 